\title{
Logistic Regression Analysis for Spatial Patterns of Drought Persistence
}

\author{
Rizwan Niaz $\mathbb{D}^{1},{ }^{1}$ Xiang Zhang $\mathbb{D}^{2,3}$ Nouman Iqbal, ${ }^{1}$ Mohammed M.A. Almazah, ${ }^{4,5}$ \\ Tajammal Hussain, ${ }^{6}$ and Ijaz Hussain $\left(\mathbb{1}^{1}\right.$ \\ ${ }^{1}$ Department of Statistics, Quaid-i-Azam University, Islamabad, Pakistan \\ ${ }^{2}$ National Engineering Research Center of Geographic Information System, School of Geography and Information Engineering, \\ China University of Geosciences (Wuhan), Wuhan 430074, China \\ ${ }^{3}$ State Key Laboratory of Information Engineering in Surveying, Mapping, and Remote Sensing (LIESMARS), Wuhan University, \\ Wuhan 430079, China \\ ${ }^{4}$ Department of Mathematics, College of Sciences and Arts (Muhyil), King Khalid University, Muhyil 61421, Saudi Arabia \\ ${ }^{5}$ Department of Mathematics and Computer, College of Sciences, Ibb University, Ibb 70270, Yemen \\ ${ }^{6}$ Department of Statistics, COMSATS University Islamabad, Lahore Campus, Lahore 54000, Pakistan
}

Correspondence should be addressed to Xiang Zhang; zhangxiangsw@whu.edu.cn

Received 27 August 2021; Revised 26 September 2021; Accepted 26 October 2021; Published 22 November 2021

Academic Editor: Feng Li

Copyright (C) 2021 Rizwan Niaz et al. This is an open access article distributed under the Creative Commons Attribution License, which permits unrestricted use, distribution, and reproduction in any medium, provided the original work is properly cited.

\begin{abstract}
Drought is one of the natural hazards with potentially significant impacts on society, economy, and other natural resources over the globe. However, the understanding of drought characteristics and its persistence can significantly help to reduce the potential impacts of drought. Moreover, the knowledge about the spatiotemporal pattern of seasonal drought frequency and drought persistence is important for water resource management, agricultural development, energy consumption, and crop yields. Therefore, the present study is employed to examine the seasonal drought frequency and drought persistence in the region. In this regard, the standardized precipitation index (SPI) at the three-month time scale was used to determine meteorological drought. Furthermore, the logistic regression model is used to calculate the odds and probability of drought persistence from one season to the next for the selected stations by identifying the spatial pattern of seasonal drought frequency and persistence. The potential of the current analysis is validated on six selected stations of the northern area of Pakistan. The outcomes related to the current analysis provide the basis for taking more considerations on early warning systems and help to make the valuable decision for water resource management and agriculture sectors in Pakistan.
\end{abstract}

\section{Introduction}

Drought is a complex phenomenon and one of the greatest recurring natural disasters. It causes substantial losses in agriculture sectors [1-6], natural ecosystems [7-9], and forestry [10-12]. It is also called a creeping phenomenon with its influences gradually take in an area over a period and may persist for a long period. In severe cases, drought can last for many years and disturb many social activities, agricultural sectors socioeconomic sectors, and environmental settings $[6,13-16]$. The arrival of drought occurrences is complicated; therefore, it is challenging to substantiate the onset of the drought occurrences. The complication in drought occurrence becomes a cause for new methodologies for the assessment of drought [17-19]. However, the effects of droughts have been described in several studies, and various extensive measures are proposed to hold them. However, without proper actions, drought consequences can be severe for the natural environment and sustained for a long period even after termination [20-22].

The speedy improvement in the drought monitoring policies brought several advantages to society $[17,18,23]$. To understand the complexity and improve methodologies of drought monitoring, the researchers have been grouping the 
drought in several aspects including meteorological, agricultural hydrological, and socioeconomic aspects [24, 25]. Rhee and Im [26] described the meteorological drought as a lack of precipitation in a prolonged period [27, 28]. The agricultural and hydrological droughts can be defined as periods with insufficient soil moisture and river flow or groundwater, respectively [29]. The drought-related socioeconomic occurs due to a shortage in water resource systems. In this case, the water demands are not fully attained by the water supply. The water supply is unable to provide sufficient water at a particular time for society. Since last recent years, droughts cause major factors that distress the society and its economic environment sectors around the world more than other natural hazards [30]. However, the disaster can be minimized by adopting suitable approaches to assess drought occurrences. The appropriate approaches can help to mitigate drought impacts and provide significant outcomes for further drought monitoring and mitigation policies.

In the literature, researchers added several indices for the improvement of drought mentoring policy and forecasting strategies. For instance, for identifying various drought classes in the selected area, Van Rooy, [31] proposed a rainfall anomaly index (RAI) which is designed particularly for the classification of drought classes. Furthermore, a study measured the cumulative deviation of moisture supply and added new research Palmer drought severity index (PDSI) in the literature for monitoring drought more accurately [32]. Many other drought indices were added in the literature for increasing the efficiency and accuracy to determine drought occurrences more accurately and precisely. The drought indices including Crop Moisture Index (CMI) proposed in [33], Bhalme and Mooly Drought Index (BMDI) in [34], Reclamation Drought Index (RDI) introduced in [35], National Rainfall Index (NRI) in [36], Surface-Water Supply Index (SWSI) developed in $[37,38]$ have proposed Standardized Precipitation Index (SPI). The SPI is prevalent among other indices and frequently used for drought monitoring and forecasting $[39,40]$. The obtained standardized values of SPI can be used to compare droughts in distinct climatic zones across regions. Therefore, the SPI is commonly used for assessing drought occurrences and developing new methodologies for drought monitoring and forecasting [41-43].

The current study aimed to examine the drought persistence in the selected stations. The study used logistic regression to compute odds and probability of drought persistence from one season to the next in the selected region by identifying the spatial pattern of seasonal drought frequency and persistence. The standardized precipitation index (SPI) at the three-month time scale was employed to characterize meteorological drought. Furthermore, the potential of the present study is validated on six selected stations of the northern area of Pakistan. The results associated with the present study provide the basis for taking more attention to the early warning systems and making improvements for water resource management and agriculture sectors to observe and substantiate the severity of drought in Pakistan.

\section{Methods}

2.1. Standardized Precipitation Index (SPI). The various studies consider varying drought indices to categorize and monitor drought occurrences [39, 41, 43]. Since the last decade, the use of SPI is common for drought monitoring $[41,44]$. The present study considers the SPI developed by [38] for the estimation of drought occurrences. The timeseries data ranging from January 1971 to December 2017 is used for drought characterization. The consistency of SPI is significant in climatic circumstances relating to the geographical and temporal distribution $[39,40]$. Furthermore, the simplicity in calculation makes SPI more prominent and recognized worldwide for characterization. The SPI can be computed for various times based on monthly data to observe the meteorological drought [39].

2.2. Logistic Regression Model. The drought is assessed based on SPI for the selected stations. The seasonal drought is analyzed using SPI at a three-month time scale for each selected station. The seasonal drought frequency is calculated as the total number of years in which drought SPI $\leq 1$ appears in each climate division of the selected station. The climate divisions are included as follows: (1) "December, January, February" (Winter); (2) "March, April, May" (Spring); (3) "June, July, August" (Summer); (4) "September, October, November" (Autumn). For instance, if the climate brings 10 years in which drought occurs in winter during the total number of 47 years, the drought frequency probability is $10 / 47$ or $21 \%$. Furthermore, the persistence of seasonal drought can be defined as the drought conditions staying from one season to the next. In the current analysis, drought persistence is defined as winter-spring, spring-summer, summer-autumn, and autumn-winter. For each station, the seasonal drought persistence and season combination can be expressed as the probability of persistence. The probability of persistence can be calculated as the total number of years in which drought persists from one season to season combination by dividing the total number of years in which drought appears during the first season in that climate division. For example, if the climate shows 12 years in which drought occurs in winter and drought conditions continue into spring during the 10 of those years, the drought persistence probability is $10 / 12$ or $83 \%$. Furthermore, in the present study, SPI for scale three is considered as a binary variable: drought occurs $=1$ and drought does not occur $=0$. The drought persistence can be calculated to define the impact of the influence of one season's moisture conditions on moisture conditions in the forthcoming season (Ford and Labosier, 2013). Moreover, in the current study, the logistic regression model is employed to examine the persistence of drought from one season to the coming season [45]. The logistic regression model is frequently used to examine the relationship between the binary dependent variable and one or more independent variables (Ford and Labosier, 2013). Kutner et al. [46]; stated that using an ordinary least squares regression with a binary dependent variable can lead to several issues including nonnormally distributed errors and 
predicted values in which range does not occur from 0 to 1. Therefore, logistic regression is the more suitable method for analyzing a binary dependent variable. Furthermore, various studies used a logistic regression model to predict the logit transformation of the dependent variable based on the independent variables [46-49]. The logistic regression model can be considered in the following form:

$$
F(t)=\frac{e^{t}}{e^{t}+1}=\frac{1}{1+e^{-t}},
$$

where $t$ is a linear function of an explanatory variable $x$, and the logistic function can be written as

$$
\pi(x)=\frac{e^{\alpha+\beta x}}{e^{\alpha+\beta x}+1}=\frac{1}{1+e^{-\alpha+\beta x}} .
$$

The inverse of the logistic function, the logit model, is

$$
g(x)=\frac{\rho}{1-\rho}=\alpha+\beta x,
$$

where the odds ratio of the drought occurrence is denoted by $(\rho /(1-\rho)), \alpha$ shows the intercept, and $\beta$ denotes the regression coefficient. Furthermore, the normally distributed residuals are not required in the logistic regression model. However, the error distribution between actual and predicted dependent variables follows binomial (Ford and Labosier, 2013). In the current scenario, for SPI at scale 3, the observations were perceived independently, and the binominal assumption meets [45, 47]. The use of the logistic function is beneficial as it can be considered an input with any value from negative infinity to positive infinity, whereas the output $\rho$ is remained to values between 0 and 1 and thus is explainable as a probability. The current study employed a logistic regression model for the specific season based on a binary dependent variable which is drought occurrence ( 1 = drought, $0=$ no drought $)$ and the explanatory variable is the SPI value from the previous season. The outcome of the model can be described for the given season as the log odds ratio of drought occurrence, and the relationship between the dependent and explanatory variables is represented by the slope $(\beta)$ of the logistic regression. For instance, when $\beta$ is observed negative, for the specific season, the odds of drought occurrence are negatively related to the SPI value in the previous season. In a more precise way, it can be described that the rise in the preceding season's SPI causes to decline in the odds of drought occurring in the subsequent season.

\section{Application}

The structural importance of the Northern region is important for the other regions of the country. The northern region is a geographic area that has a group of three mountain ranges, the Himalayas, Karakoram, and the Hindu Kush, which cover most of the region [50]. Many of the world's tallest peaks are found in this region, including $K-2$, Nanga Parbat, and Rakaposhi. The average altitude of Karakorum is $6,100 \mathrm{~m}$, Hindu Kush is 7,690 m, and the Himalayas is $8,848 \mathrm{~m}$ [51]. These high altitudes of mountains frequently deliver a significant portion of precipitation [50-52]. The reservoirs of the other regions are also associated with the rainfall of this region. Due to the significant importance of the region for the other parts of the country, the region is selected for analysis. Furthermore, the climatic situations of the chosen region placed vast and persistent effects on climatic environments and weather conditions of several parts of the country. The current analysis is accomplished with time-series data from January 1971 to December 2017 (see [53] for the selected region of the northern area of Pakistan (Figure 1)). The weather pattern fluctuates over the varying periods within the country which brings great socioeconomic influences. These changes in the atmosphere cause disturbance for the agriculture sectors and reservoir system of the country $[54,55]$. There are various climatic events related to global climate warming. These climatic events including rainstorms, high temperatures, and droughts are commonly considered for influencing global climate warming. However, the fluctuation of global warming becomes the source of wide-ranging impacts on the atmosphere and people in Pakistan [56-58]. Therefore, it is required greater considerations to recognize the drought incidents more instantly by adding improvements in the drought monitoring processes and methods. In this regard, the current study used logistic regression to evaluate the odds and probability of drought persistence from one season to the next in the selected region by recognizing the spatial pattern of seasonal drought frequency and persistence. The SPI at the three-month time scale is applied to characterize meteorological drought. The current study efficiently improves the capability of identifying the spatial pattern of seasonal drought frequency and persistence. The outcomes of the current analysis can be helpful for drought monitoring and mitigation policies in the selected region.

3.1. Results. The six stations were selected for the current analysis. These stations were chosen from the northern area of Pakistan. The climate of the stations is important for the other parts of the regions. Therefore, these stations were selected in the current analysis. The brief climatology of the selected stations for precipitation is given in Table 1 . The precipitation of the selected stations is used for the calculation of the SPI index. The importance of SPI is significantly high from the drought monitoring perspective. The SPI values were standardized by using varying probability distributions. Among the various probability distributions, the distributions for the varying stations were selected based on minimum Bayesian information criterion (BIC) values. The selected distribution and their BIC values are provided in Table 2. For instance, at the three-month time scale, the gamma distribution shows suitable candidacy for the Astore station. The BIC of gamma of Astore is -1279.0507 which is minimum among other distributions. Therefore, gamma distribution is used for standardization in the Astore station. The gamma distribution is also suitable for two other stations. For Bunji station, the BIC value of gamma distribution is -824.8686 and for Gupis, it has a BIC value is -1264.9476 . For the Chilas station, the BIC of $3 p$ Weibull is minimum 


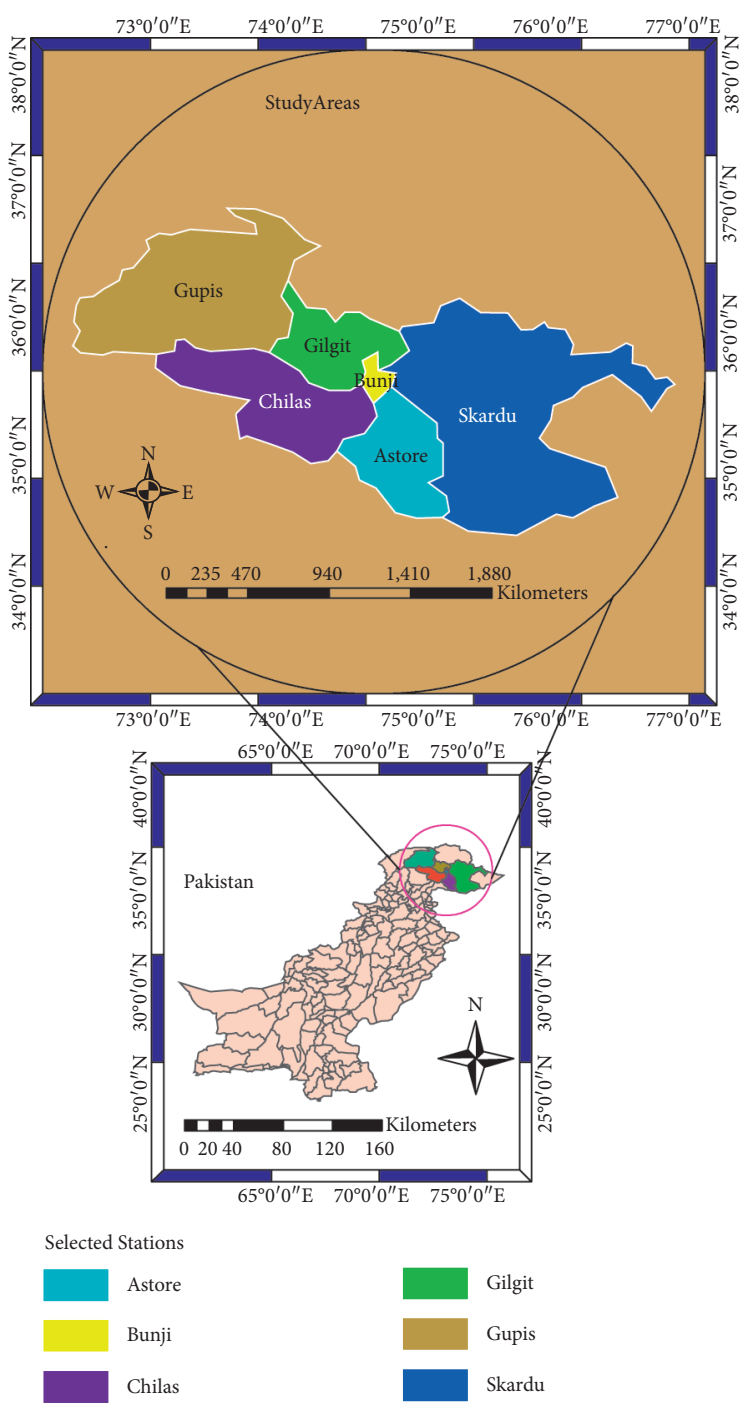

FiguRE 1: Selected geographical locations from the northern areas of Pakistan.

TABLE 1: The precipitation characteristics during the period 1971-2017 of six selected stations.

\begin{tabular}{lccccccc}
\hline Variable & Station & Mean & 1st quartile & Median & 3rd quartile & Kurtosis & Std. dev \\
\hline & Astore & 39.34 & 10.80 & 25.70 & 52.62 & 3.01 & 41.93 \\
& Bunji & 13.56 & 1.30 & 7.10 & 17.10 & 18.55 & 5.90 \\
Precipitation & Gupis & 15.94 & 0.00 & 5.70 & 19.38 & 38.21 \\
& Chilas & 15.85 & 0.95 & 7.00 & 19.32 & 8.88 & 23.53 \\
& Gilgit & 11.75 & 1.10 & 6.05 & 14.72 & 9.93 & 16.57 \\
& Skardu & 19.51 & 2.30 & 9.10 & 26.75 & 5.60 \\
\hline
\end{tabular}

among other distributions and selected for the standardization. The exponential distribution is suitable for the Gilgit station with minimum BIC (-810.2190). In Skardu station, the precipitation data is used for the standardization based on the generalized extreme value (GEV) distribution. The GEV has minimum BIC among other distributions, and therefore, selected for the standardization. Moreover, after standardization, the next step is the drought characterization which is done by the classified values of SPI.
Drought frequency is calculated by the total number of months with SPI $\leq 1$ divided by the total number of months from January 1971 to December 2017. In this way for the current analysis, the seasonal drought frequency is calculated. To calculate seasonal drought frequency, the percentage of seasons in which drought SPI $\leq 1$ occurs over the whole studied period for winter, spring, summer, and autumn, respectively. Furthermore, drought is a complicated phenomenon, and its impacts affect the agriculture, 


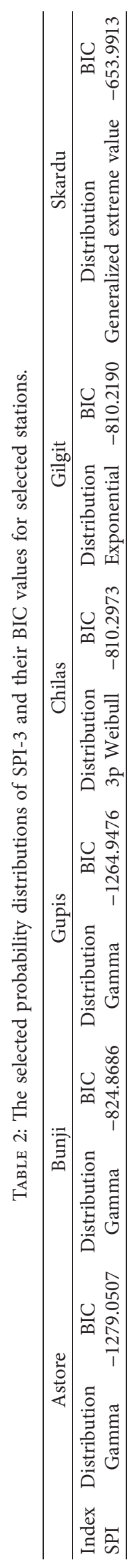



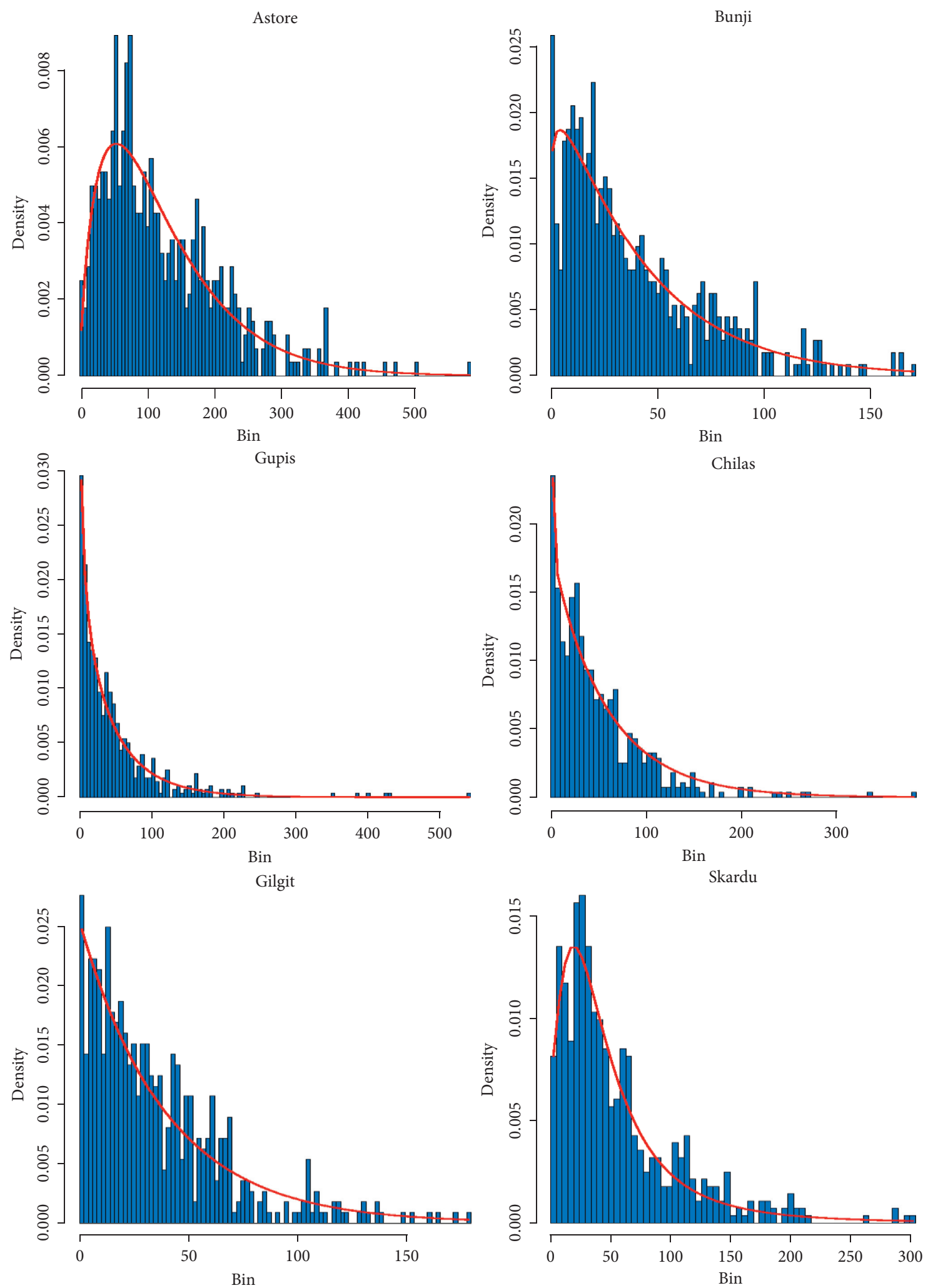

Figure 2: The varying distributions are selected for the six selected stations. The histograms (theoretical vs. empirical) of the selected distributions are presented for SPI-3.

economy, and other social activities. If meteorological drought sustains a prolonged time, it can be hazardous for soil moisture and evapotranspiration and lead to agriculture and hydrological drought. Furthermore, information about seasonal drought frequency and drought persistence are essential for water resource management, 

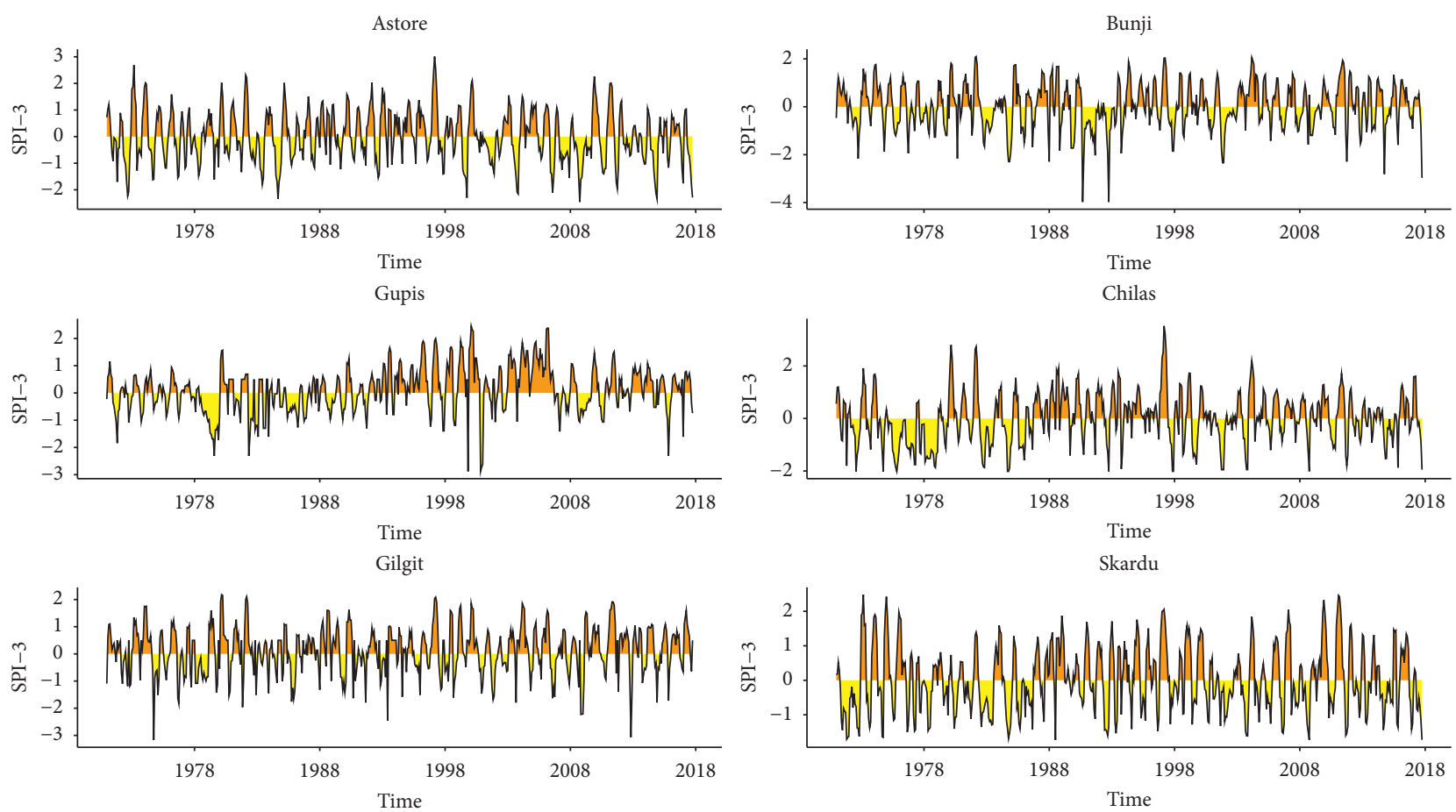

FIgURE 3: The temporal plots for SPI-3 at selected stations.

agricultural development, and energy consumption. Therefore, the study is applied to determine the frequency of meteorological drought and its persistence in various seasons in the selected stations. The seasonal drought persistence can be expressed by the probability of the persistence and computed as the total number of years in which drought remains from one season to another divided by the overall years in which drought occurs during the first season. Furthermore, the logistic regression is used to compute odds and probability of drought persistence from one season to the next in the selected stations by finding the spatial pattern of seasonal drought frequency and persistence. For example, the logistic regression model is used for winter-spring in the selected stations separately to observe odds for drought occurrences in the current season based on the SPI values of the previous season. The logistic regression model for selected stations based on springsummer is used to observe drought occurrences. Similarly, the outcomes can be obtained from the logistic regression model for summer-autumn and autumn-winter. Moreover, the results obtained from the various seasons using logistic regression and their spatial characteristics are described by the maps, and the temporal aspects are demonstrated by the graphs.

Moreover, in Figure 2, theoretical and empirical distributions for SPI at a three-month time scale (SPI-3) are presented, and the temporal behavior of selected stations for SPI-3 can be observed in Figure 3. Figure 4 shows the temporal variation for the numbers of months/year with SPI $\leq 1$. Figure 5 represents the counts of drought occurrence in the selected stations in various seasons. It can be observed that the ND category prevails among other categories in various seasons of the selected stations. Furthermore, SPI $\leq 1$ specifies the drought in the selected stations and greater than 1 shows that there is no drought. The selected stations their latitude and longitude and average months of $\mathrm{SPI} \leq 1$ is presented in Figure 6. These average months show that the overall, number of months with SPI $\leq 1$ in each year varies 6 to 12 months with an average of 10 in the Astore station from the time-series data ranging from January 1971 to December 2017. However, in Bunji station, the number of months with SPI $\leq 1$ in each year varies from 6 to 12 months with an average of 9.8085. Furthermore, average months' SPI $\leq 1$ for the other selected stations is also calculated based on the same rationale. Seasonal drought frequency is calculated as percentage of seasons in which drought (SPI) occurs over the whole study period for winter, spring, summer, and fall, respectively, and are presented in Figure 7 . The probability maps in Figure 8 demonstrate the stations that are more vulnerable to prolonged meteorological drought. For example, 90 to $100 \%$ summer drought persistence probability in summer-autumn means that 90 to $100 \%$ of summer meteorological drought in selected stations of the northern areas of Pakistan can persist to the autumn. It can be observed that there are large spatial variations in seasonal drought persistence. A strong difference is shown in various seasons with stations. The Skardu station has a lower probability of autumn-winter drought persistence than other stations. Drought persistence probabilities in springsummer and summer-autumn show a more similar pattern among the selected stations. This indicates that, in these seasons, the precipitation occurrences are not sufficient. Furthermore, the drought persistence probabilities in northern areas during summer to autumn are higher than in 

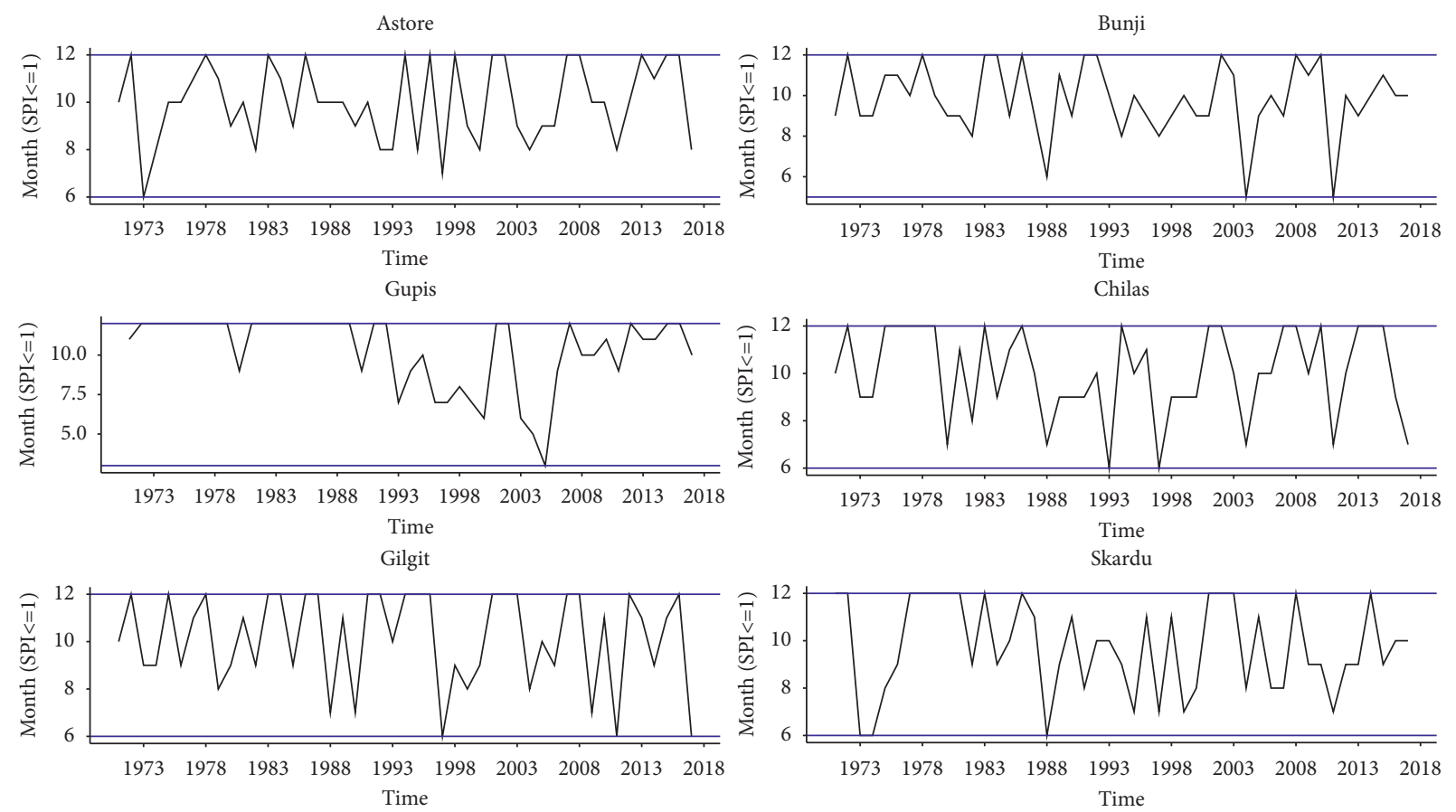

Figure 4: Time series plot: temporal behavior of SPI $\leq 1$ in selected stations.
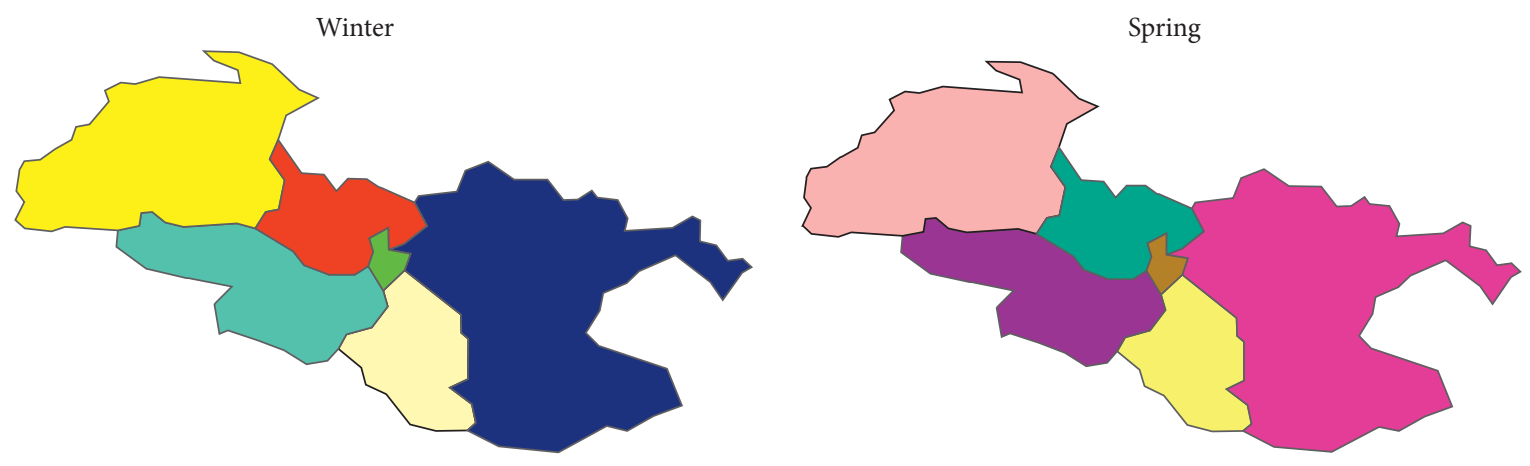

Counts
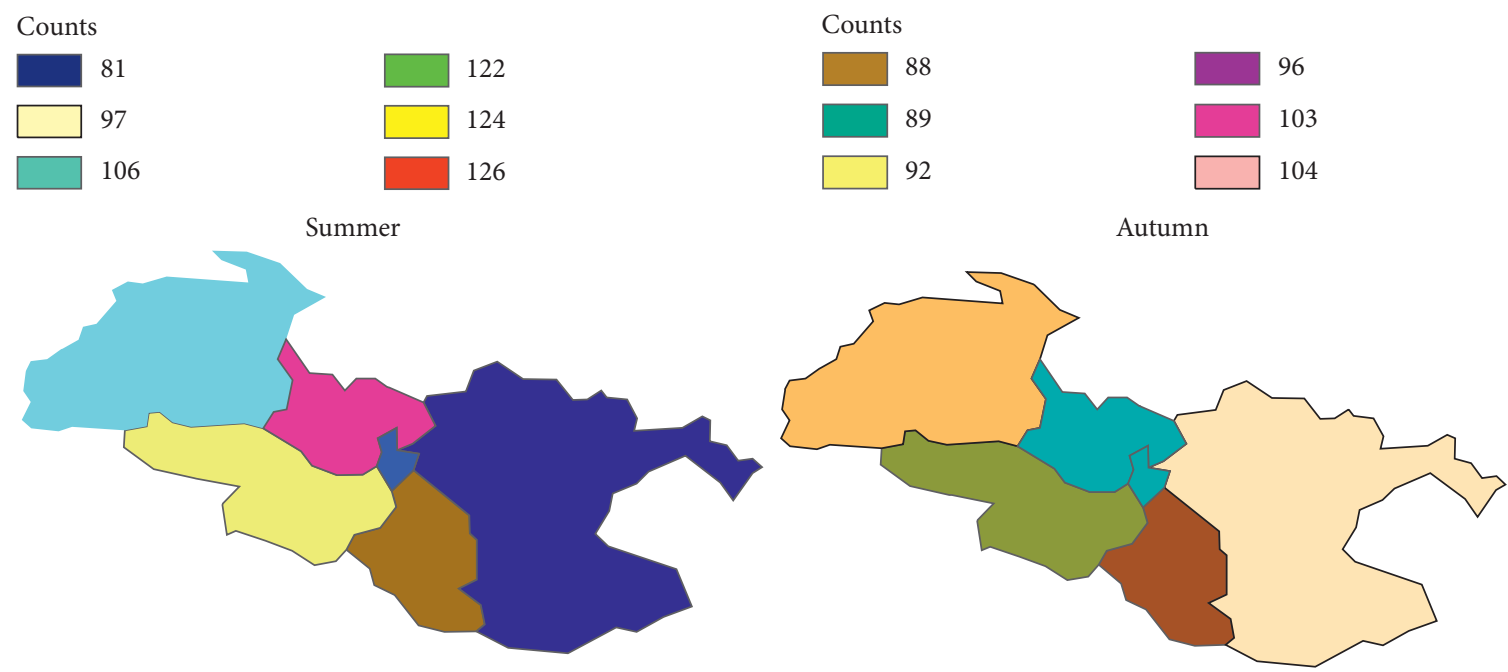

Counts

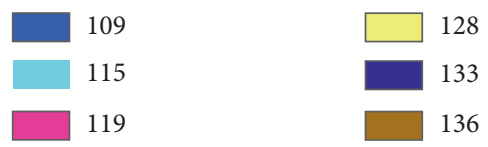

Counts

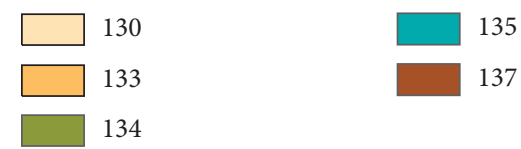

FIGURE 5: The total number of counts with SPI $\leq 1$ in the selected stations for SPI- 3 in various seasons. 


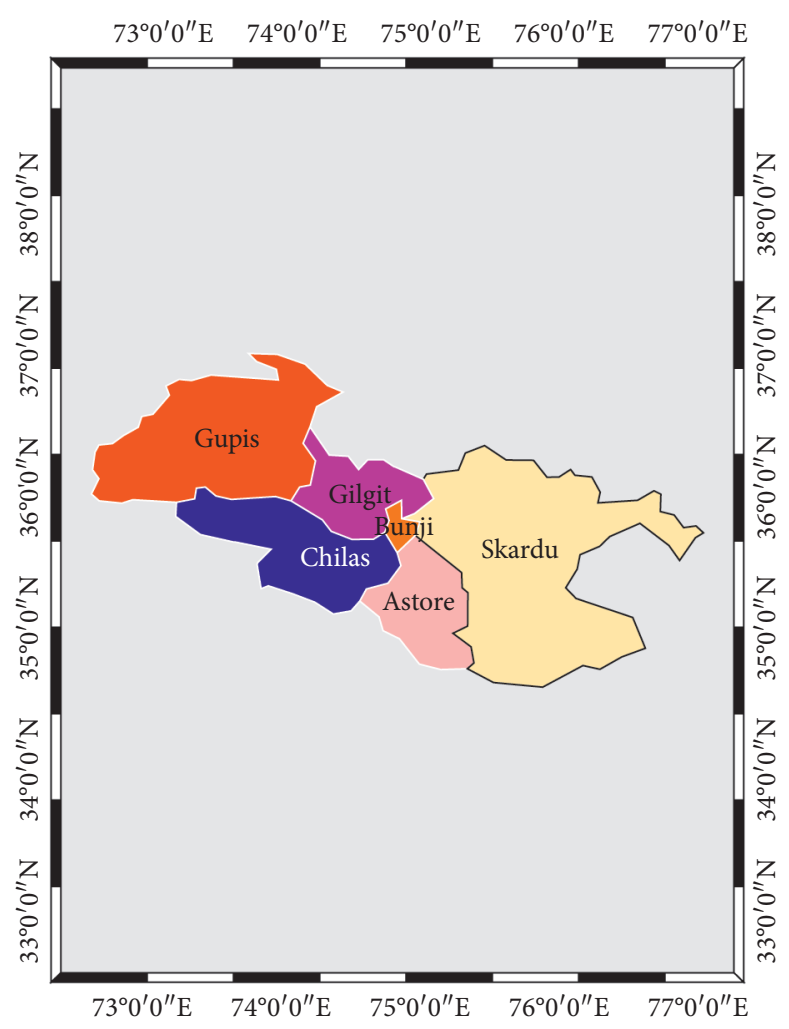

Average Month $\mathrm{SPI}<=1$

\begin{tabular}{l|l}
9.7234 & 10.0426 \\
9.8085 & 10.1489 \\
10 & 10.3191
\end{tabular}

FIgURE 6: The latitude and longitude of the selected stations and their monthly averages for SPI $\leq 1$.

other seasons. Seasonal drought persistence odds ratios output from the logistic regression model presented in various maps of Figure 9. This shows drought occurrence odds ratio changes as a function of a 1 unit increase in the previous season's SPI. The stations with an odds ratio $<1$ indicate a decreased odds ratio of drought occurrence in the given season when the SPI of the previous increases while those stations with odds ratio $>1$ showing that a positive increase in the odds ratio of drought occurrence in the given season when previous season's SPI increases. Furthermore, the significant odds ratio can be observed in the maps. The stations outline bolded are those at which the logistic regression fit is statistically significant at $\alpha<0.05$. For instance, on Gupis station in spring to summer, the odds ratio is significant and shows that as increases 1 unit in the SPI of spring the odds of drought occurrence are decreasing in summer by 0.20 to $<1 \%$. Furthermore, the relationship between various seasons and SPI is negative in selected stations. This means for increases 1 unit in the SPI, the odds of drought occurrence are negatively influenced. Similarly, the odds ratio of drought occurrence can be observed for other stations and seasons. Based on the obtained results drought early warning policies should be prepared in the selected stations accordingly. Moreover, the obtained results from the recent evaluation about seasonal drought frequency and drought persistence can be helpful to water resource management, agricultural development, energy consumption, and crop yields.

3.2. Discussion. The data of precipitation is used for the classification of drought occurrences. These drought occurrences are used to classify the drought categories in the selected region. The classified values of the drought are calculated using SPI-3. The SPI provides the standardized values for the given precipitation in the selected station for monthly data. The varying probability distributions were used for the standardization of the precipitation values for SPI. The selection of the distributions is based on BIC values. Information related to seasonal drought frequency and drought persistence play a vital role in water resource management, agricultural development, energy consumption, and crop yields. Despite their importance to the water resource management and agriculture sectors, there are very few studies available in the literature that focus on seasonal drought frequency and drought persistence [45]. Therefore, dynamic procedures are required in drought monitoring for providing relief to affected areas. Suitable drought monitoring is a key factor in preparation for water resources and disaster mitigation and making a climate-resilient society 

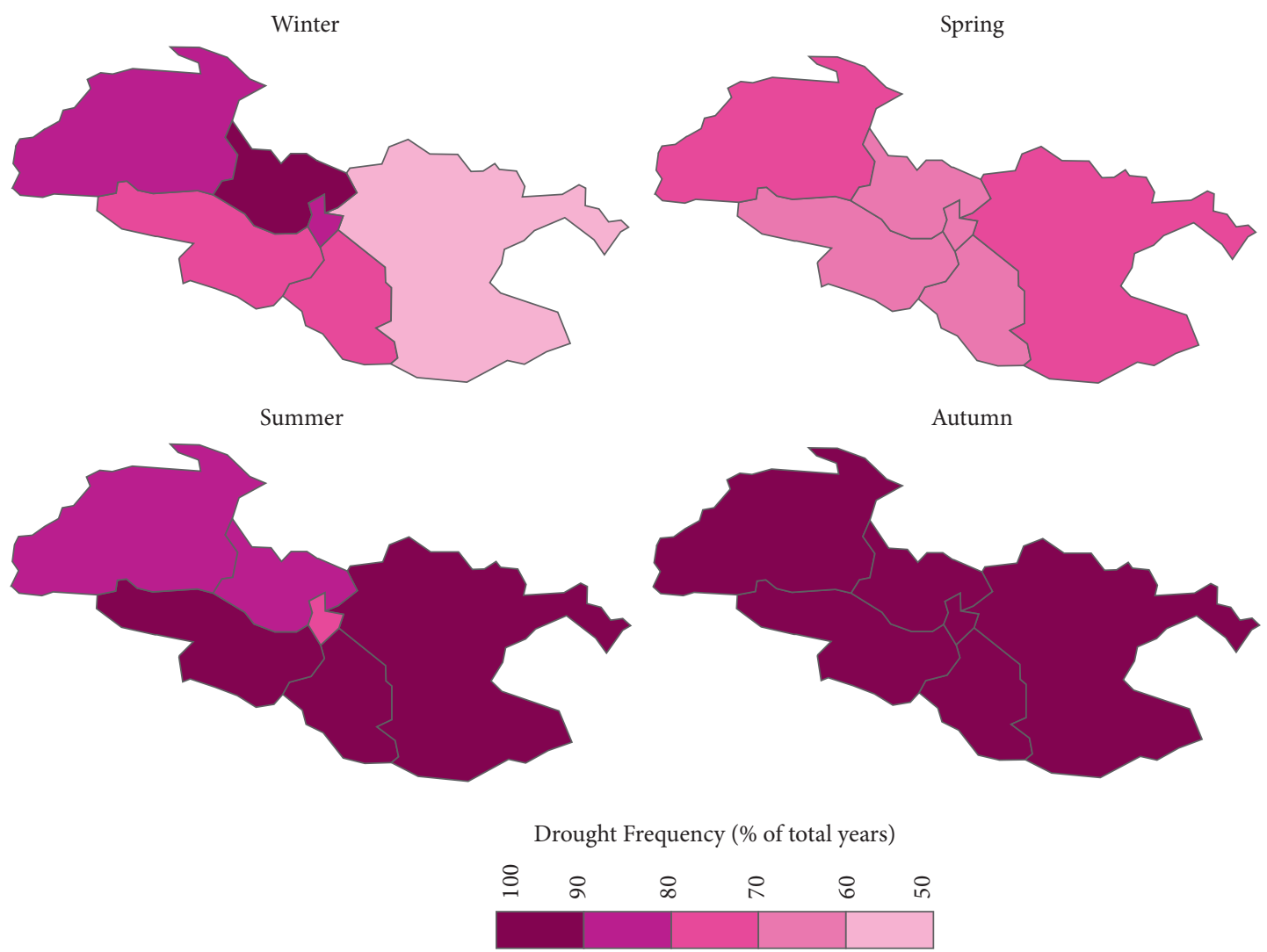

FIGURE 7: Seasonal drought frequency for each selected station as a percent of total (1971-2017) years.
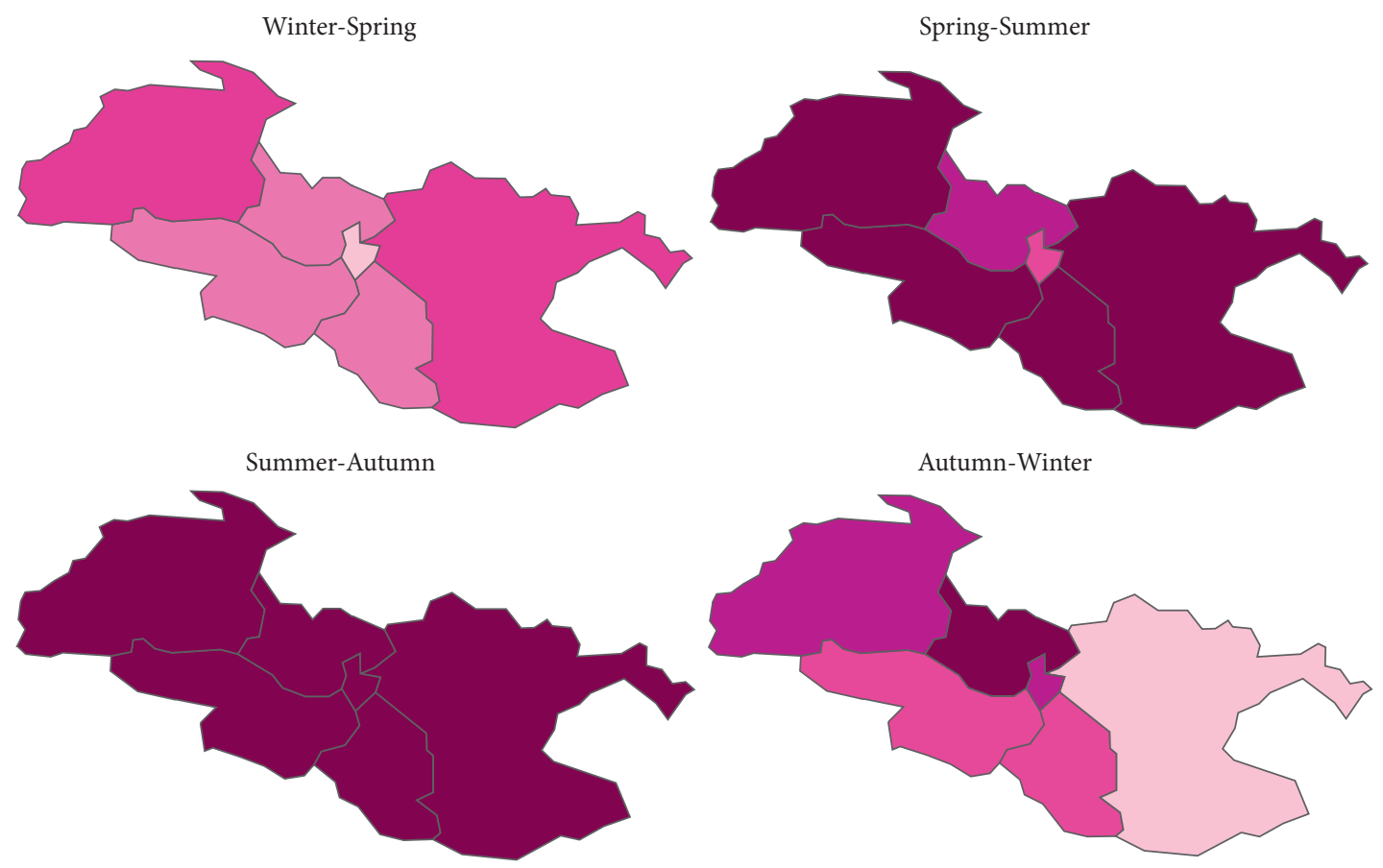

Drought persistence (\% probability)

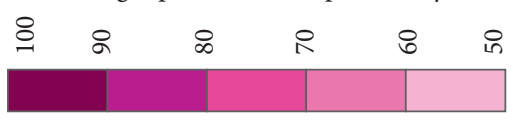

FIGURE 8: Drought persistence percent probability for all seasons in the selected stations. 

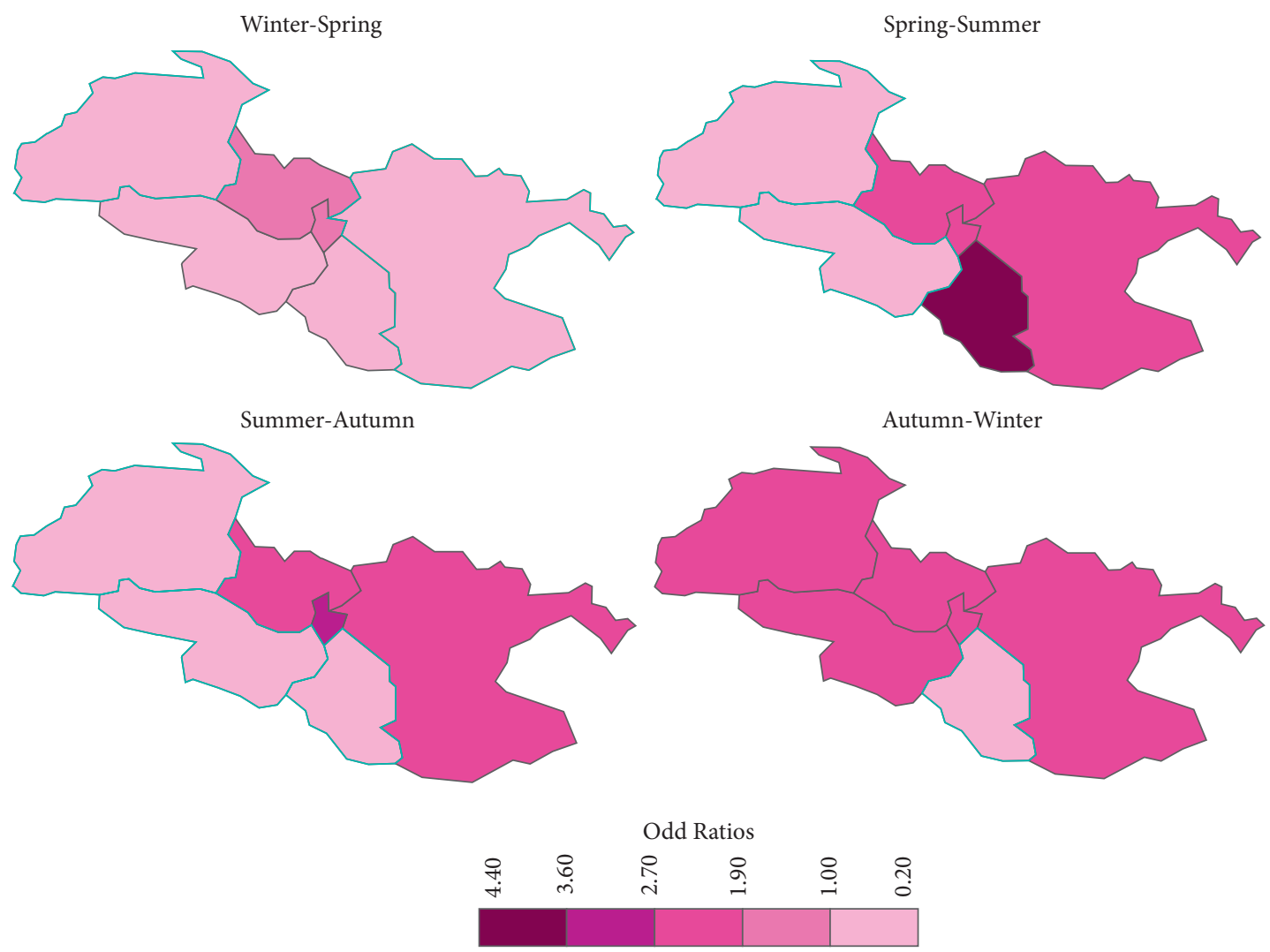

FIgURE 9: Odds ratio for various seasons in the selected stations. The relationship in the bolded stations is significant at $\alpha<0.05$.

[59-61]. The present study is employed to identify the seasonal drought frequency and drought persistence in the region. However, none of the authors have worked to identify the seasonal drought frequency and drought persistence for Pakistan in previous research. Therefore, it is a new approach in terms of spatial patterns of drought persistence in northern areas, Pakistan. The outcome of the current analysis effectively works for early warning and mitigation policies and enhances the competencies in forecasting procedures, making better management, and planning to decrease the vulnerability of society to drought and its forgoing impacts.

\section{Conclusion}

Drought is a kind of complex recurrent climatic phenomenon, least understood to monitor and challenging for the past several decades. Because of the significant influences, various techniques have been developed to overcome its impacts. Due to the development of new methodologies, the drought characteristics have been monitored more accurately. Information about the drought characteristics and its persistence provides the direction to the water resource management and agriculture sectors to minimize the negative impacts of drought. Therefore, the current study used logistic regression to analyze the odds and probability of drought persistence from one season to the next in the selected stations by identifying the spatial pattern of seasonal drought frequency and persistence. From the results, we observed that the ND category is prevailing among other categories in various seasons of the selected stations. Furthermore, the seasonal drought frequency is found significantly high in summer and autumn. The spring meteorological drought in selected stations of the northern areas of Pakistan can persist to the summer with the probability of 90 to $100 \%$. The drought persistence percent probability for summer to autumn is highest among other climate divisions. Furthermore, it was observed that there are large spatial variations in seasonal drought persistence in various seasons and stations. However, the probabilities of drought persistence in spring-summer and summer-autumn show a more similar pattern among the selected stations. However, the Skardu station has a lower probability of autumn-winter drought persistence. Moreover, the odds ratios from the logistic regression model for the seasonal drought persistence showed that the significant relationship between various seasons and SPI is negative in selected stations. This means increases 1 unit in the SPI the odds of drought occurrence are negatively influenced. The Astore, Gupis, Chilas, and Gilgit found significant at $\alpha<0.05$ in various seasons. Moreover, the current analysis is applied for the present situation and application site; however, for other climatic conditions results cannot be generalized. As climatology conditions of the regions vary, the results can be affected for the assessment of drought occurrence. Furthermore, the use of other indices can significantly increase the capabilities for drought monitoring and its persistence in the selected region. The outcomes associated with the 
present assessment provide the basis for getting more considerations on early warning systems and can be used for decision-making.

\section{Data Availability}

The data used for the preparation of the manuscript are available from the corresponding author upon request.

\section{Conflicts of Interest}

The authors declare that they have no conflicts of interest.

\section{Acknowledgments}

The authors extend their appreciation to the Deanship of Scientific Research at King Khalid University for funding this work under grant number (RGP.1/26/42), received by Mohammed M. Almazah (https://www.kku.edu.sa). This work was supported by grants from the National Natural Science Foundation of China program (41801339) and Hubei Provincial Natural Science Foundation of China (2020CFB615).

\section{References}

[1] J. Lorenzo-Lacruz, S. M. Vicente-Serrano, J. I. López-Moreno, S. Beguería, J. M. García-Ruiz, and J. M. Cuadrat, “The impact of droughts and water management on various hydrological systems in the headwaters of the Tagus River (central Spain)," Journal of Hydrology, vol. 386, no. 1-4, pp. 13-26, 2010.

[2] S. Beguería, S. M. Vicente-Serrano, F. Reig, and B. Latorre, "Standardized precipitation evapotranspiration index (SPEI) revisited: parameter fitting, evapotranspiration models, tools, datasets and drought monitoring," International Journal of Climatology, vol. 34, no. 10, pp. 3001-3023, 2014.

[3] B. Dobson, G. Coxon, J. Freer, H. Gavin, M. MortazaviNaeini, and J. W. Hall, "The spatial dynamics of droughts and water scarcity in England and Wales," Water Resources Research, vol. 56, no. 9, Article ID e2020WR027187, 2020.

[4] M. Alamgir, N. Khan, S. Shahid et al., "Evaluating severityarea-frequency (SAF) of seasonal droughts in Bangladesh under climate change scenarios," Stochastic Environmental Research and Risk Assessment, vol. 34, no. 2, pp. 447-464, 2020.

[5] D. Rodziewicz and J. Dice, "Drought risk to the agriculture sector," Economic Review, vol. 105, no. 2, 2020.

[6] P. Kalura, A. Pandey, V. M. Chowdary, and P. V. Raju, "Assessment of hydrological drought vulnerability using geospatial techniques in the tons river basin, India," Journal of the Indian Society of Remote Sensing, pp. 1-15, 2021.

[7] I. Raev and B. Rosnev, "The impact of drought on natural forest ecosystems," in Drought in Bulgaria, pp. 117-136, Routledge, England, UK, 2018.

[8] L. Deng, C. Peng, D. G. Kim et al., "Drought effects on soil carbon and nitrogen dynamics in global natural ecosystems: a meta-analysis," Earth-Science Reviews, vol. 214, Article ID 103501, 2020.

[9] I. R. Orimoloye, J. A. Belle, and O. O. Ololade, "Drought disaster monitoring using MODIS derived index for drought years: a space-based information for ecosystems and environmental conservation," Journal of Environmental Management, vol. 284, Article ID 112028, 2021.
[10] C. Grossiord, "Having the right neighbors: how tree species diversity modulates drought impacts on forests," New Phytologist, vol. 228, no. 1, pp. 42-49, 2020.

[11] B. Schuldt, A. Buras, M. Arend et al., "A first assessment of the impact of the extreme 2018 summer drought on Central European forests," Basic and Applied Ecology, vol. 45, pp. 86-103, 2020.

[12] A. L. Long, "Disturbance and sustainability in forests of the western United States," Drought, vol. 992, 2021.

[13] S. Huang, P. Li, Q. Huang, G. Leng, B. Hou, and L. Ma, "The propagation from meteorological to hydrological drought and its potential influence factors," Journal of Hydrology, vol. 547, pp. 184-195, 2017.

[14] M. Masoudi and M. Elhaeesahar, "GIS analysis for vulnerability assessment of drought in Khuzestan province in Iran using standardized precipitation index (SPI)," Iran Agricultural Research, vol. 38, no. 2, pp. 9-16, 2019.

[15] V. Marchionni, E. Daly, G. Manoli, N. J. Tapper, J. P. Walker, and S. Fatichi, "Groundwater buffers drought effects and climate variability in urban reserves," Water Resources Research, vol. 56, no. 5, 2020.

[16] S. E. Abdel-Ghany, F. Ullah, A. Ben-Hur, and A. S. N. Reddy, "Transcriptome analysis of drought-resistant and droughtsensitive sorghum (Sorghum bicolor) genotypes in response to peg-induced drought stress," International Journal of Molecular Sciences, vol. 21, no. 3, p. 772, 2020.

[17] A. D. Cameron, "Mitigating the risk of drought-induced stem cracks in conifers in a changing climate," Scandinavian Journal of Forest Research, vol. 34, no. 8, pp. 667-672, 2019.

[18] A. Gazol, J. J. Camarero, R. Sánchez-Salguero et al., "Drought legacies are short, prevail in dry conifer forests and depend on growth variability," Journal of Ecology, vol. 108, no. 6, pp. 2473-2484, 2020.

[19] A. AghaKouchak, A. Mirchi, K. Madani et al., Anthropogenic Drought: Definition, Challenges, and Opportunities, AGU, Washington, DC, USA, 2021.

[20] A. Hamdy and G. Trisorio-Liuzzi, Drought Planning and Drought Mitigation Measures in the Mediterranean Region, AGU, Washington, DC, USA, 2001.

[21] R. Ragab and A. Hamdy, "Water management strategies to combat drought in the semiarid regions," Water Management for Drought Mitigation in the Mediterranean, pp. 47-112, Centre International de Hautes Etudes Agronomiques Méditerranéennes, Tecnomack-Bari, Italy, 2004.

[22] E. Gidey, O. Dikinya, R. Sebego, E. Segosebe, and A. Zenebe, "Predictions of future meteorological drought hazard ( 2070) under the representative concentration path (RCP) 4.5 climate change scenarios in Raya, Northern Ethiopia," Modeling Earth Systems and Environment, vol. 4, no. 2, pp. 475-488, 2018.

[23] M. A. Nayak and W. U. Hassan, "A synthesis of drought prediction research over India," Water Security, vol. 13, Article ID 100092, 2021.

[24] D. A. Wilhite, Drought as a Natural Hazard: Concepts and Definitions, AGU, Washington, DC, USA, 2000.

[25] O. V. Wilhelmi, K. G. Hubbard, and D. A. Wilhite, "Spatial representation of agroclimatology in a study of agricultural drought," International Journal of Climatology, vol. 22, no. 11, pp. 1399-1414, 2002.

[26] J. Rhee and J. Im, "Meteorological drought forecasting for ungauged areas based on machine learning: using long-range climate forecast and remote sensing data," Agricultural and Forest Meteorology, vol. 237-238, pp. 105-122, 2017.

[27] S. Jiang, L. Wei, L. Ren et al., "Utility of integrated IMERG precipitation and GLEAM potential evapotranspiration 
products for drought monitoring over mainland China," Atmospheric Research, vol. 247, Article ID 105141, 2021.

[28] H. Salimi, E. Asadi, and S. Darbandi, "Meteorological and hydrological drought monitoring using several drought indices," Applied Water Science, vol. 11, no. 2, pp. 1-10, 2021.

[29] B. Clausen and C. P. Pearson, "Regional frequency analysis of annual maximum streamflow drought," Journal of Hydrology, vol. 173, no. 1-4, pp. 111-130, 1995.

[30] A. Dai, "Drought under global warming: a review," WIREs Climate Change, vol. 2, no. 1, pp. 45-65, 2011.

[31] M. P. Van Rooy, "A rainfall anomally index independent of time and space," NOTOS, vol. 14, 1965.

[32] W. C. Palmer, "Meteorological drought," US Department of Commerc, vol. 30, 1965.

[33] W. C. Palmer, "Keeping track of crop moisture conditions, nationwide: the new Crop Moisture Index," Weatherwise, vol. 21, no. 4, pp. 156-161, 1968.

[34] H. N. Bhalme and D. A. Mooley, "Large-scale droughts/floods and monsoon circulation," Monthly Weather Review, vol. 108, no. 8, pp. 1197-1211, 1980.

[35] K. M. Weghorst, The Reclamation Drought Index: Guidelines and Practical Applications, vol. 6, Bureau of Reclamation, Denver, CO, USA, 1996.

[36] R. Gommes and F. Petrassi, "Rainfall variability and drought in sub-Saharan Africa," vol. 630, 1996.

[37] B. A. Shafer and L. E. Dezman, "Development OF surface water supply index (SWSI) to assess the severity OF drought condition IN snowpack runoff areas," in Proceedings of the Western Snow Conference, Fort Collins, CO, USA, 1982, January.

[38] T. B. McKee, N. J. Doesken, and J. Kleist, "The relationship of drought frequency and duration to time scales," in Proceedings of the 8th Conference on Applied Climatology, Boston, MA, USA, 1993, January.

[39] I. Nalbantis and G. Tsakiris, "Assessment of hydrological drought revisited," Water Resources Management, vol. 23, no. 5, pp. 881-897, 2009.

[40] D. H. Mlenga, A. J. Jordaan, and B. Mandebvu, "Integrating standard precipitation index and normalised difference vegetation index for near-real-time drought monitoring in Eswatini," Jamba (Potchefstroom, South Africa), vol. 11, no. 1, pp. 917-919, 2019.

[41] T. Caloiero and S. Veltri, "Drought assessment in the sardinia region (Italy) during 1922-2011 using the standardized precipitation index," Pure and Applied Geophysics, vol. 176, no. 2, pp. 925-935, 2019.

[42] T. Javed, Y. Li, S. Rashid et al., "Performance and relationship of four different agricultural drought indices for drought monitoring in China's mainland using remote sensing data," The Science of the Total Environment, vol. 759, Article ID 143530, 2021.

[43] O. Singh, D. Saini, and P. Bhardwaj, "Characterization of meteorological drought over a dryland ecosystem in northwestern India," Natural Hazards, vol. 42, 2021.

[44] J. P. Bloomfield and B. P. Marchant, "Analysis of groundwater drought building on the standardised precipitation index approach," Hydrology and Earth System Sciences, vol. 17, no. 12, pp. 4769-4787, 2013.

[45] C.-Y. J. Peng, K. L. Lee, and G. M. Ingersoll, "An introduction to logistic regression analysis and reporting," The Journal of Educational Research, vol. 96, no. 1, pp. 3-14, 2002.

[46] M. H. Kutner, C. J. Nachtsheim, J. Neter, and W. Li, Applied Linear Statistical Models, University of Minnesota, Minneapolis, Minnesota, 2005.
[47] T. Ford and C. F. Labosier, "Spatial patterns of drought persistence in the Southeastern United States," International Journal of Climatology, vol. 34, no. 7, pp. 2229-2240, 2014.

[48] S. Bachmair, C. Svensson, I. Prosdocimi, J. Hannaford, and K. Stahl, "Developing drought impact functions for drought risk management," Natural Hazards and Earth System Sciences, vol. 17, no. 11, pp. 1947-1960, 2017.

[49] L. Meng, T. Ford, and Y. Guo, "Logistic regression analysis of drought persistence in East China," International Journal of Climatology, vol. 37, no. 3, pp. 1444-1455, 2017.

[50] G. Rasul, Q. Z. Chaudhry, A. Mahmood, K. W. Hyder, and Q. Dahe, "Glaciers and glacial lakes under changing climate in Pakistan," Pakistan Journal of Meteorology, vol. 8, no. 15, 2011.

[51] Y. Latif, M. Yaoming, M. Yaseen, S. Muhammad, and M. A. Wazir, "Spatial analysis of temperature time series over the Upper Indus Basin (UIB) Pakistan," Theoretical and Applied Climatology, vol. 139, no. 1, pp. 741-758, 2020.

[52] M. Adnan, G. Nabi, M. Saleem Poomee, and A. Ashraf, "Snowmelt runoff prediction under changing climate in the Himalayan cryosphere: a case of Gilgit River Basin," Geoscience Frontiers, vol. 8, no. 5, pp. 941-949, 2017.

[53] R. Niaz, I. Hussain, Z. Ali et al., "A novel spatially weighted accumulative procedure for regional drought monitoring," Tellus A: Dynamic Meteorology and Oceanography, vol. 72, no. 1, pp. 1-13, 2020.

[54] S. A. Anjum, L. Wang, J. Salhab, I. Khan, and M. F. Saleem, "An assessment of drought extent and impacts in agriculture sector in Pakistan," Journal of Food Agriculture and Environment, vol. 8, no. 2, pp. 1359-1363, 2010.

[55] S. Hina and F. Saleem, "Historical analysis (1981-2017) of drought severity and magnitude over a predominantly arid region of Pakistan," Climate Research, vol. 78, no. 3, pp. 189-204, 2019.

[56] K. Ahmed, S. Shahid, and N. Nawaz, "Impacts of climate variability and change on seasonal drought characteristics of Pakistan," Atmospheric Research, vol. 214, pp. 364-374, 2018.

[57] N. Khan, D. A. Sachindra, S. Shahid, K. Ahmed, M. S. Shiru, and N. Nawaz, "Prediction of droughts over Pakistan using machine learning algorithms," Advances in Water Resources, vol. 139, Article ID 103562, 2020.

[58] N. Mazhar, M. Nawaz, A. I. Mirza, and K. Khan, "Sociopolitical impacts of meteorological droughts and their spatial patterns in Pakistan," South Asian Studies, vol. 30, no. 1, 2020.

[59] A. H. Payab and U. Türker, "Comparison of standardized meteorological indices for drought monitoring at northern part of Cyprus," Environmental Earth Sciences, vol. 78, no. 10, pp. 1-19, 2019.

[60] O. O. Ayantobo and J. Wei, "Appraising regional multicategory and multi-scalar drought monitoring using standardized moisture anomaly index (SZI): a water-energy balance approach," Journal of Hydrology, vol. 579, p. 124139, 2019.

[61] N. Puletti, W. Mattioli, F. Bussotti, and M. Pollastrini, "Monitoring the effects of extreme drought events on forest health by Sentinel-2 imagery," Journal of Applied Remote Sensing, vol. 13, no. 2, Article ID 020501, 2019. 